\title{
Physico-chemical Properties of High and Low Amylose Rice Flour
}

\author{
K. Kemashalini, B.D. Rohitha Prasantha*, K.A.K.L. Chandrasiri \\ Department of Food Science and Technology, Faculty of Agriculture, University of Peradeniya, 20400, Sri Lanka \\ *Email: bdrp@pdn.ac.1k
}

\begin{abstract}
Physico-chemical and pasting properties of high-amylose rice flour ( $\mathrm{Bg} 360)$ and lowamylose rice flour (At 405) were tested in this study. A modified visco-amylograph method was used to test the pasting behavior of rice flours. Amylose content, damaged starch, swelling power, water absorption capacity and sedimentation volume showed a significant difference between the two rice flours. The At 405 rice flour contained significantly higher damage starch content (\%), swelling power (g/g), water absorption capacity (\%) and low crude fat content (\%) compare to Bg 360 . The amylose content of rice flour showed a strong but negative correlation with damaged starch, swelling power and water absorption capacity of rice flour. Damaged starch showed a significant positive correlation with swelling power and water absorption capacity. Despite the breakdown of the viscosity ( $\mathrm{mPa} s$ ) did not show significant differences, setback viscosity, pasting temperature and time of high-amylose flour showed significantly higher values than low-amylose flour.
\end{abstract}

Keywords: Amylose; physico-chemical; rice flour; viscosity, crude fat, crude protein

\section{Introduction}

Rice (Oryza sativa L.) is the most important staple food in Asia and its flour is a good substitute for wheat flour. In Sri Lanka, rice flour is used to make many household food products for all three meals. Wheat flour causes irritation in the digestive tract of those who are suffering from gluten-intolerant. On the other hand, Sri Lanka totally depends on the imported wheat flour for bakery products. Rice flour can be successfully incorporated into the bread, noodles, cakes, biscuits and other bakery products $[1,2$, $3]$ as an alternative to the wheat flour due to its pasting nature. It is also used as a thickening agent in recipes that are refrigerated or frozen since it inhibits liquid separation from solid dough.

Starch is composed of essentially linear amylose and highly branched amylopectin polymers. Amylose has an ability to form a firm gel during the gelatinization process and prone to retrogradation during storage, whereas amylopectin shows low syneresis and high resistance to starch retrogradation. The amylose content of the rice starch varies among the different rice cultivars. Based on the amylose: amylopectin ratio rice varieties can be classified based on their amylose content such as waxy rice (1-2\% amylose), very low amylose rice (2- $12 \%$ amylose), low amylose rice (12-20\% amylose), intermediate amylose rice (20-25\% amylose) and high amylose rice (25-33\% amylose) [4]. A high-amylose rice grains increases their volume and become flakiness during cooking, but become harder upon cooling. In contrast to that low-amylose rice grains are kept in moist and sticky conditions after cooking [5].

Although Sri Lanka has developed many improved rice varieties named as $\mathrm{Bg}(\approx 43$ varieties), Bw $(\approx 16$ varieties $)$, Ld $(\approx 8$ varieties $)$ and At $(\approx 17$ varieties $)$, about $99 \%$ of them can be classified as highintermediate amylose rice. According to the available data, only At 405 can be classified as commercialized low-amylose rice variety $[6,7,8]$. The amylose content of the rice starch directly affects the cooking and sensory properties of rice $[7,9]$. It is a well-known fact that other physico-chemical and functional properties are also changed with the amylose content of rice $[8,10,11]$. On the other hand, amylose/amylopectin ratio, a fine structure of amylopectin, a chain length of amylose, and their crystalline nature greatly affects the physico-chemical and functional properties of rice starches, such as pasting properties, gelatinization and retrogradation [5]. Rheological characteristics of starch in rice flour determine their application as a raw material for food industrial application. Rice varieties with higher amylose content are more prone to leaching out solids into the cooking water during cooking as starch from the damaged starch granules [4, 12]. Therefore, structure and composition of amylose and 
amylopectin caused greater influence on the physico-chemical and functional properties of rice flour/starches during food processing [13].

Sri Lanka has many traditional and improved rice cultivars since long but, we exactly do not know the suitability of those rice flour for production of rice base product-development such as biscuits, noodles and confectionery products etc. The main reason is that, although we have a quite high number of improved high-amylose rice varieties, we have only two low-amylose rice varietal cultivars to produce rice flour. According to our previous experience, low-amylose rice flour types are suitable for industrial application than high-amylose rice flour. Therefore, the objective of this study was to evaluate the diversity of the physico-chemical, and pasting properties of two indica cultivars having low and high amylose rice varieties grown in Sri Lanka.

\section{Materials and Methods}

\subsection{Sample Preparation}

Raw rice samples of $\mathrm{Bg} 360$ (high-amylose) and At 405 (low-amylose) were collected from the Ambalanthota, Rice Research Institute, Sri Lanka. Rice samples were de-husked using a laboratory dehusker (Model P-1, NgekSengHuat, Thailand) and then polished by using a laboratory rice polisher (Model K-1, NgekSengHuat, Thailand). Milled rice samples were ground into flour using pin mill (Alpine, Augsburg, Germany). Flour samples were packed in an airtight high-density polypropylene bag and stored in a refrigerated $\left(4{ }^{\circ} \mathrm{C}\right)$ until its further use for analysis.

\subsection{Flour Composition}

Crude protein and crude fat contents of rice samples were determined according to AACC [14] standard methods. The amylose content of the rice flour was measured by iodine colorimetric method [4]. The absorbance was measured using a UV-visible spectrometer (Shimadzu, UV-1601, Japan) at $620 \mathrm{~nm}$. The Amylose content was determined by standard amylose curve prepared using analytical grade potato amylase starch (Sigma-Aldrich, UK).

\subsection{Damaged Starch}

Damaged starch was measured according to the procedure described by Dermott [15] with some modifications. About $0.5 \mathrm{~g}$ flour was weighed into a $100 \mathrm{ml}$ conical flask and $10 \mathrm{ml}$ of $1.67 \%$ Trichloro acetic acid and $10 \mathrm{ml}$ of $5.0 \%$ Potassium thiocyanate was added into the flask. The sample was extracted for 15 minutes by manually shaking in every $3 \mathrm{~min}$ intervals. The suspension was first filtrated and then $2 \mathrm{ml}$ of starch solution was pipetted into a $25 \mathrm{ml}$ volumetric flask containing $15 \mathrm{ml}$ of distilled water. After adding one milliliter iodine solution, the mixture was made up to the volume with distilled water and left for 10 minutes. Finally the absorbance was measured at $600 \mathrm{~nm}$ using an UVVIS spectrophotometer (UV 1601, Shimadzu, Japan). Then the damaged starch was calculated by the difference between the total amylose content and the measured amylose content in the sample.

\subsection{Swelling Power}

Swelling power was determined following the method described by Leach et al. [16]. One gram of the sample was mixed with $10 \mathrm{ml}$ distilled water in a centrifuge tube and heated at $80 \pm 2{ }^{\circ} \mathrm{C}$ for 30 minutes. The mixture was continually shaken during the heating period. After heating, the suspension was centrifuged at $3000 \times \mathrm{g}$ for $15 \mathrm{~min}$. The supernatant was decanted and weight of the paste taken. Swelling power was calculated based on the wet basis using equation 1.

where:

$$
\text { Swelling power }(g / g)=\frac{m_{1}}{m_{0}}
$$

$\mathrm{m}_{\mathrm{o}}=$ Initial weight of sample $(\mathrm{g})$

$\mathrm{m}_{1}=$ Sediment weight after centrifuge $(\mathrm{g})$ 


\subsection{Water Absorption}

Water absorption capacity was measured according to the procedure described by Beuchat [17]. One gram sample was weighed into $25 \mathrm{ml}$ graduated centrifuge tube and then added about $10 \mathrm{ml}$ water. The suspension was allowed to stand at room temperature of $28{ }^{\circ} \mathrm{C}$ for one hour. The suspension was centrifuged (Himac CT 4D, Japan) at $2000 \times \mathrm{g}$ for $30 \mathrm{~min}$. Water absorption capacity was calculated based on the wet basis using following equation 2 .

$$
\text { Water absorption capacity }(w . b \%)=\frac{m_{1}-m_{o}}{m_{o}} \times 100
$$

where:

$\mathrm{m}_{\mathrm{o}}=$ Initial weight of sample $(\mathrm{g})$

$\mathrm{m}_{1}=$ Sediment weight after centrifuge $(\mathrm{g})$

\subsection{Sedimentation}

The degree of sedimentation of flour suspended in a lactic acid solution during a standard time interval was measured as sediment volume [18]. Rice flour sample of $5 \mathrm{~g}$ and $50 \mathrm{ml}$ of $0.2 \%$ lactic acid were added into a $100 \mathrm{ml}$ graduated cylinder. The cylinder was shaken by hand for about $10 \mathrm{~s}$ and then $50 \mathrm{ml}$ of lactic acid solution was added into the suspension. The cylinder was inverted five times and placed in a $35{ }^{\circ} \mathrm{C}$ water bath. Readings of the sediment volume were taken at 5,30 and 60 min intervals.

\subsection{Particle Size}

Particle size distribution was analyzed using the series of standard sieves (ISO 3310-1, USA). The sieves were stacked in descending order of aperture $200 \mu \mathrm{m}, 150 \mu \mathrm{m}, 100 \mu \mathrm{m}$ and $40 \mu \mathrm{m}$ in size. Rice flour sample of $200 \mathrm{~g}$ was placed on top of the larger aperture size sieve and manually shaken for $30 \mathrm{~min}$. Weight of the sample retained on each sieve was recorded at the end of the sieving.

\subsection{Pasting Behaviour}

The pasting behavior of high and low amylose rice flours was tested using an alternative method to visco-amylograph technique reported by Steffe et al. [19] and ISI [20]. The method was slightly modified prior to the experiment. According to the visco-amylogrph pattern of $8 \%$ (wt/wt) potato starch slurry (Sigma-Aldrich, Germany), the alternative method was further standardized using literature data of peak viscosity, pasting temperature and time to reach a peak viscosity [21].

According to the alternative method, the coaxial viscometer method was used to measure the viscosity of the heated slurry of rice flour samples. Rice flour sample of $7.4 \mathrm{~g}$ was suspended in $92.6 \mathrm{ml}$ of distilled water to prepare $8 \%$ (wt/wt) flour slurry in a $100 \mathrm{ml}$ beaker. The rice flour slurry was heated to $95{ }^{\circ} \mathrm{C}$ at a constant rate of $1.1 \pm 0.1{ }^{\circ} \mathrm{C} /$ min using a water bath (Memmert-WNB 14, Germany) while continuous stirring the suspension. The sample was kept at $95 \pm 0.2{ }^{\circ} \mathrm{C}$ for $20 \mathrm{~min}$, and then the temperature was being gradually fallen to $50{ }^{\circ} \mathrm{C}$ within 15 min under the running tap water. The viscosity of the sample was measured using coaxial viscometer (Brookfield Model-DVE, USA) at $60 \mathrm{rpm}$ speed. During the test, the temperature of the flour slurry and the water bath was recorded every 5 min and $1 \mathrm{~min}$ intervals, respectively. A T-type thermocouples and data logger (TC08-PicoTech, UK) was used to record the temperature during the viscosity measurement. The viscosity properties of two rice flour pastes were studied based on the peak viscosity (maximum viscosity between the heating and holding cycles), through viscosity (minimum viscosity after peak/ hot paste viscosity) and final viscosity (viscosity of the paste after cooling). For comparison, following viscosity values (equations 3, 4 and 5) were also derived from the above viscosity values. All values were recorded in millipascal per second $(\mathrm{mPa} s)$ and obtained from the time-temperature-viscosity graphs. Pasting temperature $\left({ }^{\circ} \mathrm{C}\right)$, peak viscosity temperature $\left({ }^{\circ} \mathrm{C}\right)$ and peak viscosity time $(\mathrm{min})$ were also recorded. The measurements were obtained in triplicate.

Breakdown viscosity $(\mathrm{mPa} \mathrm{s})=$ peak viscosity - through viscosity

Setback viscosity ( $\mathrm{mPa} \mathrm{s})$ = final viscosity - peak viscosity

Consistency $(\mathrm{mPa} \mathrm{s})=$ final viscosity - through viscosity 


\subsection{Statistical Analysis}

Values were recorded as mean \pm standard deviation (SD) of triplicate determinations. Data were analyzed by simple t-test. The Pearson's correlation coefficient was used to study correlations between all the tested parameters of rice samples at $\mathrm{P}<0.05$. All statistical data were analyzed using SAS version 6 .

\section{Results}

\subsection{Flour Composition}

The damaged starch content (\%), swelling power $(\mathrm{g} / \mathrm{g})$, water absorption capacity (\%), amylose content (\%), crude protein (\%) and crude fat (\%) of high and low-amylose rice varieties are presented in Table 1. Amylose and crude fat contents of $\mathrm{Bg} 360$ rice flour were significantly higher $(\mathrm{P}<0.05)$ than the amylose and fat contents of At 405 rice flour. Rice varieties of $\mathrm{Bg} 360$ and At 405 showed amylose contents of $31.1 \pm 0.3 \%$ and $14.5 \pm 0.2 \%$ respectively. The crude fat content of the At 405 rice flour sample was significantly lower $(\mathrm{P}<0.05)$ than that of the Bg 360 rice flour. Approximately $44 \%$ higher crude fat was contained in the $\mathrm{Bg} 360$ than that in the At 405 low-amylose rice. Although the cured protein content did not show any significant differences $(\mathrm{P}>0.05)$ between two rice flour, At 405 has slightly higher crude protein content than Bg 360 .

\subsection{Damaged Starch}

The damaged starch content of $\mathrm{Bg} 360$ was significantly lower $(\mathrm{P}<0.05)$ than the damage starch content of At 405 rice flour. According to the results (Table 1), the damaged starch content of At 405 rice flours was recorded as 1.6 times higher than the damaged starch content of $\mathrm{Bg} 360$. The damaged starch content of Bg 360 and At 405 rice flours was $2.64 \pm 0.18 \%$ and $4.17 \pm 0.61 \%$, respectively.

Table 1. Physico-chemical properties of high and low amylose rice flour types

\begin{tabular}{lllllll}
\hline & \multicolumn{5}{c}{ Physico-chemical properties $( \pm \mathrm{SD})$} \\
\cline { 2 - 7 } Rice flour & $\begin{array}{l}\text { Damaged } \\
\text { starch }(\%)\end{array}$ & $\begin{array}{l}\text { Swelling power } \\
(\mathrm{g} / \mathrm{g})\end{array}$ & $\begin{array}{l}\text { Water absorption } \\
\text { capacity }(\%)\end{array}$ & $\begin{array}{l}\text { Amylose } \\
\text { content }(\%)\end{array}$ & $\begin{array}{l}\text { Crude } \\
\text { protein }(\%)\end{array}$ & $\begin{array}{l}\text { Crude fat } \\
(\%)\end{array}$ \\
\hline Bg 360 & $2.6 \pm 0.2^{*}$ & $6.3 \pm 0.1^{*}$ & $196.8 \pm 2.5^{*}$ & $31.1 \pm 0.3^{*}$ & $7.8 \pm 0.2$ & $2.5 \pm 0.1^{*}$ \\
At 405 & $4.2 \pm 0.6$ & $7.1 \pm 0.1$ & $248.5 \pm 4.2$ & $14.5 \pm 0.2$ & $8.4 \pm 0.4$ & $1.4 \pm 0.4$ \\
\hline
\end{tabular}

$*$ Mean \pm SD value within the same column are significantly different at $(\mathrm{P}<0.05)$

\subsection{Swelling Power}

There was a slight but significant difference $(\mathrm{P}<0.05)$ between swelling power between both rice flour (Table 1). Swelling power of low-amylose At 405 rice flour was higher than that of the swelling power of high-amylose Bg 360 rice flour.

\subsection{Water Absorption and Sedimentation}

There was a significant difference $(\mathrm{P}<0.05)$ in the water absorption capacity of two rice flours. Water absorption capacity of the At 405 flour was approximately 25\% higher than the Bg 360 flour sample. Volume of sedimentation decreases with time for both high amylose and low amylose rice flour (Figure 1). Sedimentation volume of At 405 rice flour at any equal time was significantly higher $(\mathrm{P}<0.05)$ by about $16 \%$ than the sedimentation volume of $\mathrm{Bg} 360$ rice flour. However, sedimentation volume decreased linearly $\left(\mathrm{Bg} 360: \mathrm{y}=-0.07 \mathrm{x}+28.1, \mathrm{r}^{2}=0.99\right.$; At 405: $\left.\mathrm{y}=-0.07 \mathrm{x}+24.5, \mathrm{r}^{2}=0.97\right)$ with time of both rice flour. 


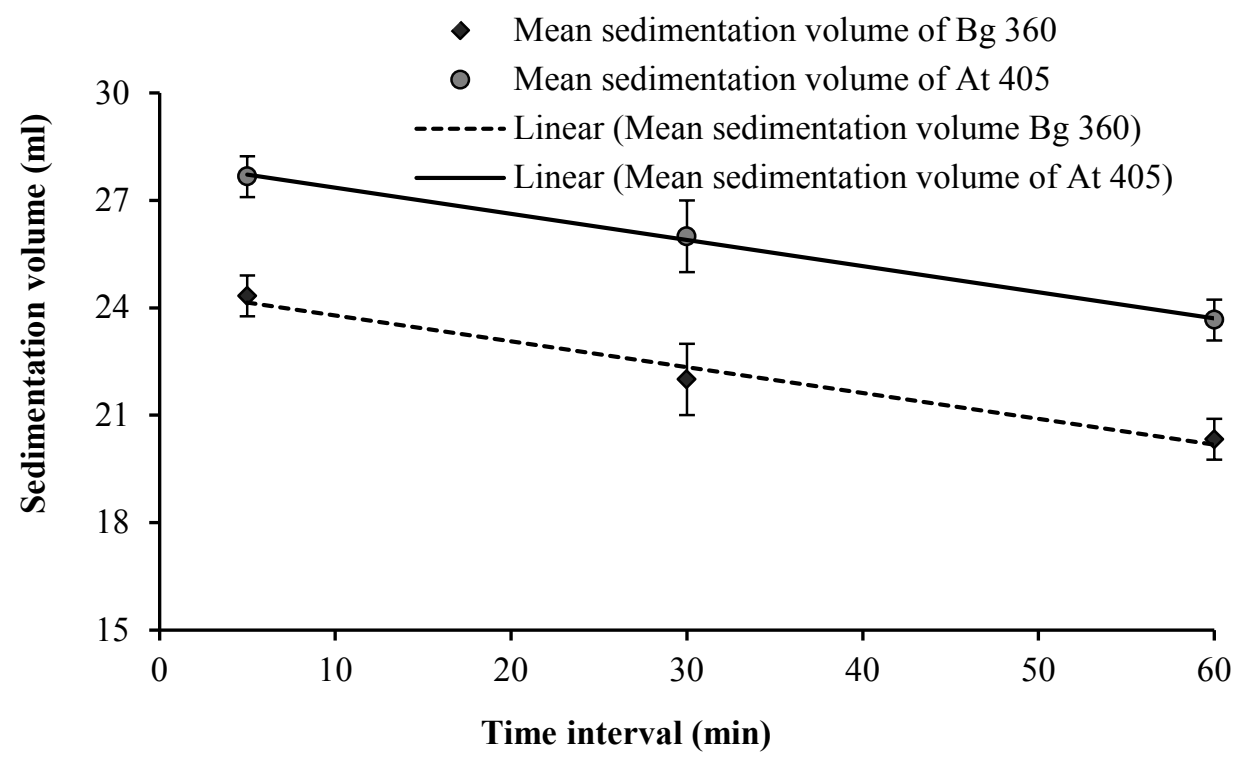

Figure 1. Sedimentation volume of At 405 and Bg 360 rice flour samples at equal time interval

\subsection{Particle Size}

Particle size of the two rice flour samples ranged between 40-200 $\mu \mathrm{m}$ with an average of 40-100 $\mathrm{\mu m}$ (Figure 2). There was a significant difference $(\mathrm{P}<0.05)$ in the particle distribution of two rice flour samples. The Bg 360 rice flour has a higher percentage of particle size than At 405 rice flour. Small amount of Bg 360 rice flour remains in the sieve of larger aperture size sieve than At 405 rice flour. The fine particle $<40 \mu \mathrm{m}$ was significantly higher $(\mathrm{P}<0.05)$ in $\mathrm{Bg} 360$ rice flour than At 405 rice flour.

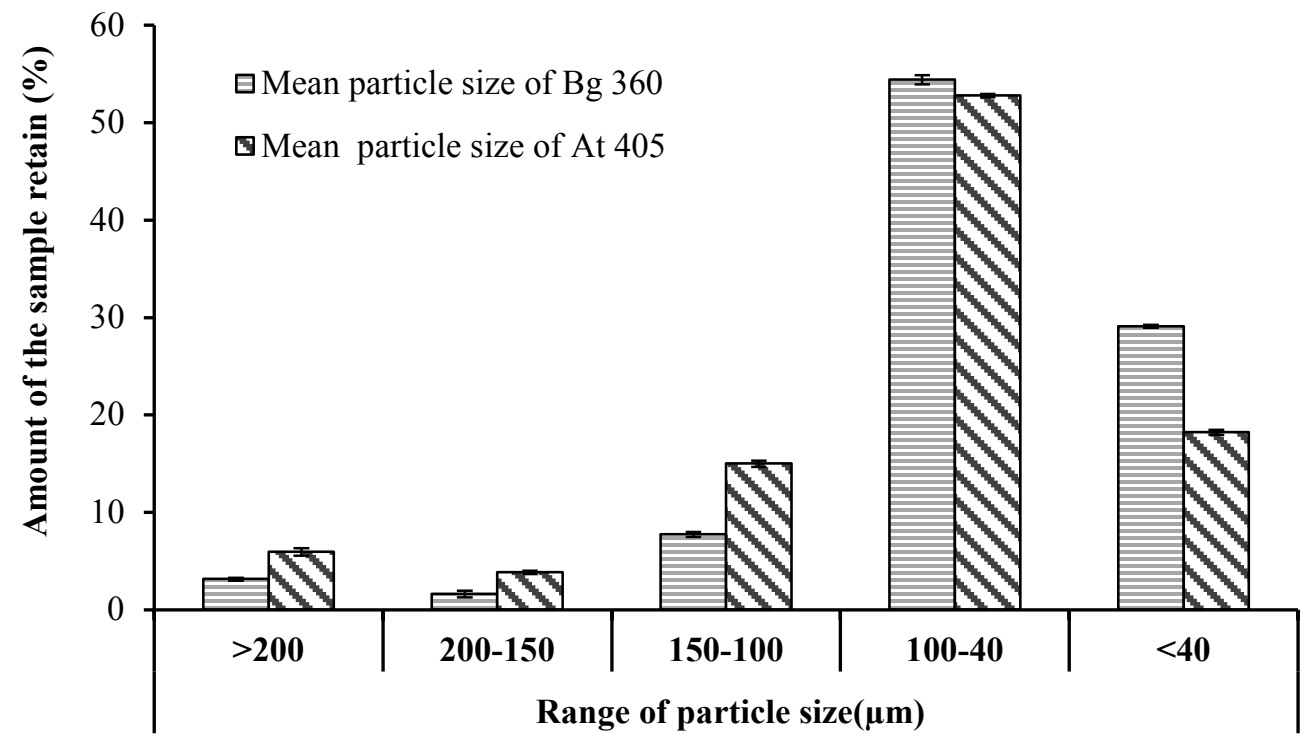

Figure 2. Particle size distribution of $\mathrm{Bg} 360$ and At 405 rice flour samples

\subsection{Pearson's Correlation Coefficients}

Correlation coefficients (r) of physico-chemical parameters between two tested rice varieties are shown in Table 2. This study found that amylose content was negatively correlated with damage starch $(\mathrm{r}=-$ $0.91 ; \mathrm{P}<0.05)$, swelling power $(\mathrm{r}=-0.96 ; \mathrm{P}<0.05)$ and water absorption capacity $(\mathrm{r}=-0.99 ; \mathrm{P}<0.01)$ 
contents, indicating that the amylose content was directly affected by the damage starch content, swelling power and water absorption capacity of the rice flour. The amount of damage starch content (\%) was highly correlated to their swelling power and water absorption capacity. It was shown by the Pearson's correlation coefficient values of $\mathrm{r}=0.94(\mathrm{P}<0.05)$ and $\mathrm{r}=0.91(\mathrm{P}<0.05)$ respectively. A higher positive correlation $(\mathrm{r}=0.98 ; \mathrm{P}<0.01)$ was found between swelling power and water absorption capacity.

Table 2. Pearson's correlation coefficient between physico-chemical characteristics of rice flour

\begin{tabular}{lllll}
\hline & $\begin{array}{l}\text { Amylose } \\
\text { content }(\%)\end{array}$ & $\begin{array}{l}\text { Damaged } \\
\text { starch }(\%)\end{array}$ & $\begin{array}{l}\text { Swelling } \\
\text { power }(\mathrm{g} / \mathrm{g})\end{array}$ & $\begin{array}{l}\text { Water absorption } \\
\text { capacity (\%) }\end{array}$ \\
\hline Amylose content (\%) & 1 & & & \\
Damaged starch (\%) & $-0.91^{*}$ & 1 & 1 & 1 \\
Swelling power (g/g) & $-0.96^{*}$ & $0.94^{*}$ & 1 & \\
Water absorption capacity (\%) & $-0.99^{* *}$ & $0.91^{*}$ & $0.98^{* *}$ & 1 \\
\hline
\end{tabular}

\subsection{Pasting Behaviour}

The pasting properties of $\mathrm{Bg} 360$ and At 405 rice flour samples were shown in time-temperatureviscosity graphs data (Figure 3). Important viscosity values, time and temperature data were directly obtained from the graphs and the pasting property values were calculated more or less similar to the visco-amylograph data [20]. All rice flour samples showed gradual increased in their viscosity with increasing the temperature. There was significant difference $(\mathrm{P}<0.05)$ of pasting properties such as peak viscosity, through viscosity, final viscosity, setback viscosity, pasting temperature and pasting time (Table 3) between high-amylose and low-amylose rice flour samples.

Table 3. Rice flour pasting properties of high and low amylose rice varieties

\begin{tabular}{lll}
\hline Property & $\begin{array}{l}\text { Bg 360 rice flour } \\
(\text { Mean } \pm \mathrm{SD})\end{array}$ & $\begin{array}{l}\text { At 405 rice flour } \\
(\text { Mean } \pm \mathrm{SD})\end{array}$ \\
\hline Peak viscosity $(\mathrm{mPa} \mathrm{s})$ & $6660 \pm 275^{\mathrm{a}^{*}}$ & $7400 \pm 329^{\mathrm{b}}$ \\
Through viscosity $(\mathrm{mPa} \mathrm{s})$ & $1116.7 \pm 126^{\mathrm{a}}$ & $2083.3 \pm 29^{\mathrm{b}}$ \\
Final viscosity (mPa s) & $8850 \pm 600^{\mathrm{a}}$ & $7233.3 \pm 208^{\mathrm{b}}$ \\
Breakdown viscosity (mPa s) & 5543.3 & 5316.7 \\
Setback viscosity $(\mathrm{mPa} \mathrm{s})$ & 2190 & -166 \\
Pasting temperature $\left({ }^{\circ} \mathrm{C}\right)$ & $67.1 \pm 0.3^{\mathrm{a}}$ & $63.4 \pm 0.4^{\mathrm{b}}$ \\
Pasting time $(\mathrm{min})$ & $30 \pm 1^{\mathrm{a}}$ & $25 \pm 2^{\mathrm{b}}$ \\
\hline Values with same superscript within a raw are not significantly different $(\mathrm{p}>0.05$
\end{tabular}

The At 405 rice flour showed significantly higher $(\mathrm{P}<0.05)$ peak viscosity $(7400 \mathrm{mPa} \mathrm{s})$ and through viscosity (2083.3 mPa s) compared to the $\mathrm{Bg} 360$ rice flour. The high-amylose $\mathrm{Bg} 360$ flour sample showed the highest final viscosity, setback value, and pasting temperature of $8850 \mathrm{mP} \mathrm{s}, 2190 \mathrm{mP}$ s and $67.1{ }^{\circ} \mathrm{C}$, respectively. However, At 405 flour sample showed the lowest setback viscosity values of -166 $\mathrm{mPa}$ s and $25 \mathrm{~min}$ of pasting time compared to the $\mathrm{Bg} 360$ rice flour sample. 


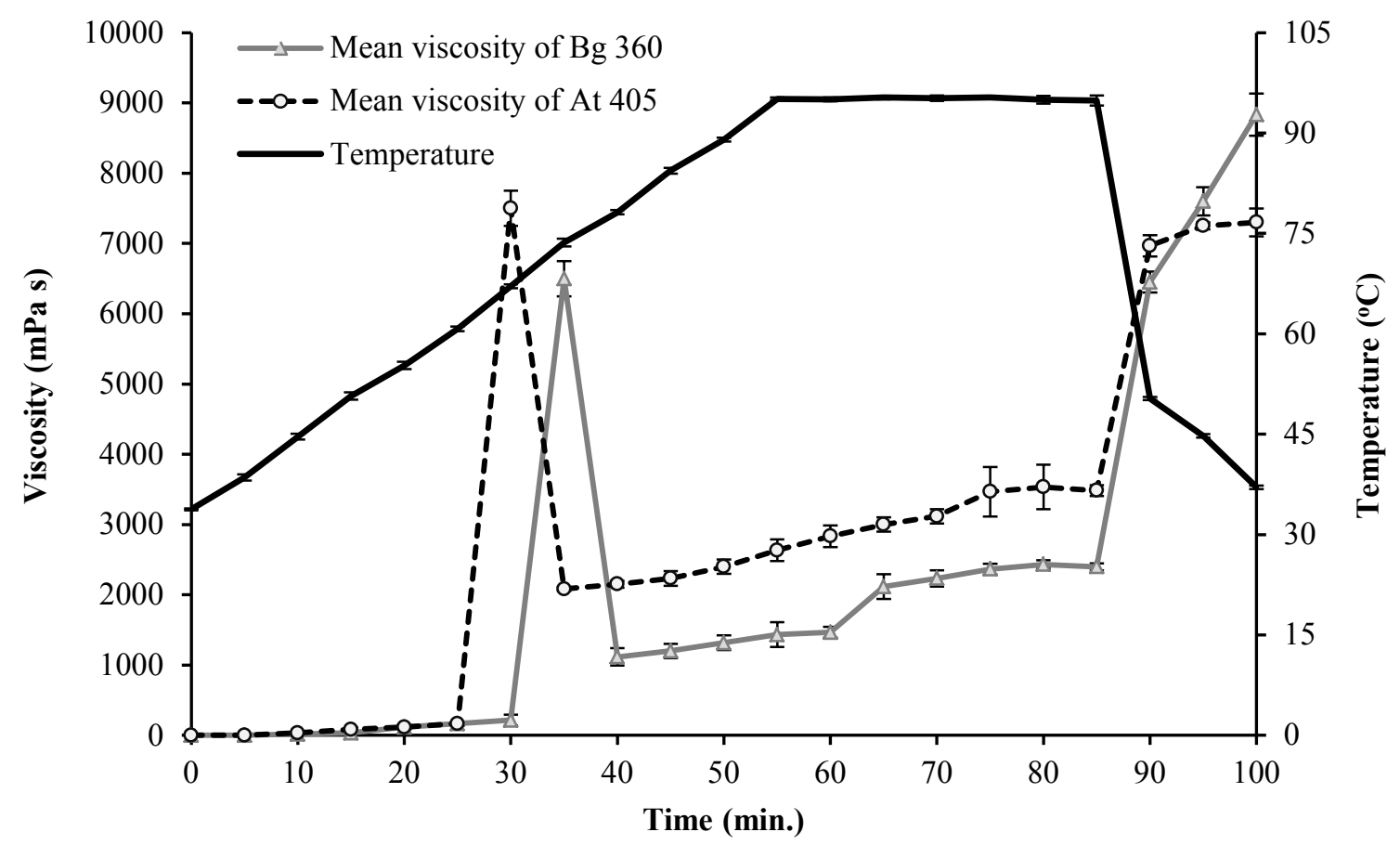

Figure 3. Viscosity behavior (mean $\pm \mathrm{SD}$ ) of $8 \%$ (wt/wt) rice flour slurry obtained from low-amylose and highamylose rice.

\section{Discussion}

The amount of amylose present in the starch granules affects the functional characteristics and physicochemical properties of starch. Despite of the amylose content can vary within the same cultivar within the same year and site of cultivation [22], it was more or less constant within the rice particular variety. According to the study of Darandakumbura et al. [6] amylose content of $\mathrm{Bg} 360$ was $31.9 \pm 0.8 \%$ and amylose content of At 405 was 14.9 $1.3 \%$. Wickramasinghe and Noda [23] and Somaratne et al. [24] have also reported the more or less similar amylose content of At 405 rice flour as $16.0 \%$ and $14.8 \%$ respectively. According to Fari et al. [25], amylose content of these two rice varieties was similar to the value of our study. Therefore, $\mathrm{Bg} 360$ and At 405 paddy varieties can be categorized as high-amylose and low-amylose rice [4]. Crude fat and protein contents also recorded in similar levels to the previous studies of two rice varieties.

Dry milling shows the highest percentage of damaged starch compared to wet milling [26] of flour due to lack of moisture remain in the rice kernels. Although both rice varieties were dry milled, damaged starch content high in low-amylose rice flour sample than high-amylose rice flour samples of At 405 and Bg 360 respectively. Williams et al. [27] reported that the extent of damage was directly proportional to the hardness of the kernel and the particle size of flour. According to Bettge et al. [28] resistant to mechanical damage of low-amylose rice flour was much lower than high-amylose rice flour. The results of this study also confirmed that At 405 was prone to more structural damage during milling due to its basmati characteristics. According to the grain size and shape, Bg 360 and At 405 were categorized as short-bold and extra along-slender type grains respectively [8]. Low-amylose rice flour of At 405 may cause less resistance to shear force and a simultaneous increase in the starch damage during the dry milling. This could be due to the less hydrogen bonding between amylose molecules in the low-amylose starch granule. Although both rice varieties undergo similar milling method, cumulative particle size distribution of $\mathrm{Bg} 360$ rice flour was higher than the particle size distribution of At 405 rice flour sample. This may have related to the size difference of starch granules exist in the two rice varieties. It has been stated that the blending of rice flour with low damaged starch content with desirable amylose content gives the best flour quality for bakery products [13]. There was a relationship between other physico- 
chemical properties and swelling power of rice flour. Swelling power showed a negative correlation with the amylose content and positive correlation with the damaged starch. Low-amylose rice, especially with high amount of damage starch can increase the water absorption and hence increase the swelling power of low amylose rice flour. Rice flour with high-amylose and low damage starch content absorbs less water due to close intact of amylose chains with starch granules. A higher positive correlation was found between swelling power and water absorption capacity indicates that both related to the structural differences between amylose and amylopectin molecules. Swelling power of starch depends on the capacity of starch molecules to form hydrogen bonding with water. Food eating quality is often connected to the retention of water in swollen starch granules, which is called as swelling power [29]. During heating, starch granules gradually swell, lose their native birefringence and loss crystalline order, but eventually form a starch paste [30]. Heat treatment of cereal starches gives rise to two stages of swelling and solubilization [31]. Starch granules are damaged and solubilized during heating. Amylose appears in the center of the granules, during the first stage of swelling [32]. But, with further increases of temperature and application of shear forces, amylose leaks out from the starch granules. The outer most amylopectin layer was fragmented and dispersed in the amylose phase [32]. However, swelling capacity decreases with the increase of amylose content, because of its long and linear polymer chain. Sedimentation capacity indirectly related to the gel-strength of the flour. The volume of sedimentation decreases with time of both high-amylose and low-amylose rice flour sample. Akatsu [18] stated that sedimentation volumes can either increase or decrease with time relative to the dough stability of the flour. Hence, it may be due to the low dough stability of rice flour volume of sedimentation decreases. Nevertheless, comparatively higher sedimentation volume was observed in the At 405 rice flour compared to Bg 360 rice flour sample. According to Kruger and Hatcher [33] sedimentation test results were influenced by the flour extraction rate, flour milling time and the type of flour milling. The results of this study showed that different level of flour extraction rate (particle size) under the same milling method. Therefore, higher sedimentation capacity may be related to the high protein content of At 405 and the formation of high gel-strength.

Pasting curves are one of the most useful techniques to evaluate the behavior of different types of rice starch. The pasting-behavior of both flour samples was in good agreement with the standard method of flour testing. The findings of this study showed that flour with high-amylose rice has high pasting temperature and low peak viscosity. However, the peak viscosity behavior of At 405 rice flour was comparatively higher than the Bg 360 flour. According to these findings, Bg 360 rice flour consists of more amylose but may have fewer long chains of amylopectin. That would lead to a reduction of swelling power and acquired low starch viscosity. Basically, the starch retrogradation relatively controlled the increase in paste viscosity, whereas shear and rupturing of swollen starch granules regulated by breakdown viscosity. Setback viscosity implies the degree of retrogradation. Therefore, At 405 rice flour has considerably low retrogradation due to very low setback viscosity, low breakdown viscosity and pasting temperature compare to $\mathrm{Bg} 360$ rice flour sample. Luh and Liu [34] reported that rice starch with high-amylose content has relatively low peak viscosity and form rigid gels on cooling while those starches with low-amylose have high peak and low setback viscosities. Varavinit et al. [35] found that the gelatinization temperatures of Thai rice starch were positively correlated with amylose content and low-amylose starch showed a low degree of retrogradation. Fitzgerald et al. [36] reported an increase peak viscosity of low lipid content rice flour. This may apply to the low-amylose At 405 rice flour where it has low crude fat and therefore showed very low setback viscosity. In contrast to our results, previous studies have reported that the protein contents of rice grain are negatively correlated with peak and breakdown viscosity but positively correlated with setback values [37]. The results of this study showed that At 405 has a slightly higher protein content, low-fat content, low setback viscosity but high pasting peak viscosity. Therefore, low-amylose rice flour has the great potential to use in the food industry application compares to the use of high-amylose rice flour.

\section{Conclusions}

In the present study, we studied the differences between high-amylose and low-amylose rice varieties in the physico-chemical properties of rice flour. The damaged starch content, swelling power, water absorption capacity and sedimentation capacity of low-amylose rice cultivars were higher to those of 
high-amylose rice. Viscosity-time-temperature characteristics data also showed remarkable differences in rice flour starch pasting properties between high-amylose and low-amylose rice varieties. Our experimental results provide some useful information for the local food industry making use of lowamylose rice varieties.

Acknowledgments. We wish to thank Ms. R.F. Hafeel, Amablanthota, Rice Research Institute and Food research division, Department of Agriculture, Sri Lanka for providing rice flour samples.

\section{Reference}

1. H. P. Sivaramakrishnan, B. Senge and P. K. Chattopadhyay, "Rheological properties of rice dough for making rice bread". Journal of Food Engineering, vol. 62, pp. 37-45, 2004.

2. H. Yano, A. Fukui, K. Kajiwara, I. Kobayashi, K. Yoza, A. Satake and M. Villeneuve, "Development of glutenfree rice bread: Pickering stabilization as a possible batter-swelling mechanism". LWT - Food Science and Technology, vol. 79, pp. 632-639, 2017.

3. M.H. Kim, "Review on rice flour manufacturing and utilization". Journal of Biosystems Engineering, vol. 38, pp. 5-15, 2013.

4. B.O. Juliano, "A simplified assay for milled rice amylose". Cereal Science Today, vol. 16, pp. 334-338, 1971.

5. M. Calingacion, L. Fang, L. Quiatchon-Baeza, R. Mumm, A. Riedel, R.D. Hall and M. Fitzgerald, "Delving deeper into technological innovations to understand differences in rice quality". Rice, 8: 6, 2015.

6. H.D.K. Darandakumbura, D.G.N.G. Wijesinghe and B.D.R. Prasantha, "Effect of processing condition and milling rate on apparent amylose content of locally grown rice verities. Tropical Agriculture Research, vol 24, pp.317-324, 2013.

7. B.D.R. Prasantha, R.F. Hafeel, K.M.S. Wimalasiri and U.P.D. Pathirana, "End-use quality characteristics of hermetically stored paddy". Journal of Stored Product Research, vol. 59, pp. 158-166, 2014.

8. H.A.P.W. Hettiarachchi, S.P. Rebeira, B.D.R. Prasantha and H.A.M. Wickramasinghe, "Diversity of physical and cooking quality characters of selected traditional and improved rice varieties in Sri Lanka". Sri Lankan Journal of Biology, vol. 1, pp. 15-26, 2016.

9. H.J. Chung, Q. Liu, L. Lee and D.Z. Wei, "Relationship between the structure, physicochemical properties and in vitro digestibility of rice starches with different amylose contents". Food Hydrocolloids, vol. 25, pp. 968-975, 2011.

10. N.S. Sodhi and N. Singh, "Morphological, thermal and rheological properties of starches separated from rice cultivars grown in India". Food Chemistry, vol. 80, pp. 99-108, 2003.

11. S. Yu, Y. Ma and D.W. Sun, "Impact of amylose content on starchretrogradation and texture of cooked milled rice during storage". Journal of Cereal Science, vol. 50, pp.139-144, 2009.

12. S.P. Rebeira, H.A.M. Wickramasinghe, W.L.G. Samarasinghe and B.D.R. Prasantha, "Diversity of grain quality characteristics of traditional rice (Oryza sativa L.) varieties in Sri Lanka". Tropical Agricultural Research, vol 25, pp. 470- 478, 2014.

13. E. Araki, K. Ashida, N. Aoki, M. Takahashi and S. Hamada, "Characteristics of rice flour suitable for the production of rice flour bread containing gluten and methods of reducing the cost of producing rice flour". Japan Agricultural Research Quarterly, vol. 50, pp. 23-31, 2016.

14. AACC "Approved Methods of the American Association of Cereal Chemists". Methods 14-50 and 44-15A. AACC International, St. Paul, Minnesota, USA, 2000.

15. E.E.M. Dermott, "The rapid non-enzymatic determination of damaged starch in flour". Journal of science food agriculture, vol. 31, pp. 405-413, 1980.

16. H.W. Leach, L.D.M. Cowen and T.J. Schoch, "Structure of the starch granules; Swelling and solubility patterns of various starches". Cereal Chemistry, vol. 36, pp. 534-544, 1959.

17. L.R. Beuchat, "Functional and electrophoretic characteristics of succinylated peanut flour protein". Journal of Agriculture Food Chemistry, vol. 25, pp. 258- 261, 1977.

18. S. Akatsu, "A method for the selection of a suitable flour to make products such as bread, noodles, confectionery items". Japanese patent 676, 1954. 
19. J.F. Steffe, M.E. Castellperez, K.J. Rose and M.E. Zabik, "Rapid testing method for characterizing the rheological behavior of gelatinizing corn starch slurries. Cereal Chemistry, vol. 66, pp. 65-68, 1989.

20. ISI "ISI-17-1e Determination of starch viscosity by Brookfield". International Starch Institute. (2002). http://www.starch.dk/ISI/methods/17brookfield.htm (Last retrieved on August 12, 2018)

21. H.E. Grommers, D.O. van der Krogt, "Potato starch: production, modifications and uses". In: J. BeMiller, R. Whistler (Eds.), Starch chemistry and technology, Academic Press, London, pp 511-540, 2009.

22. Y. Suzuki, Y. Sano, T. Ishikawa, T. Sasaki, U. Matsukura and H. Hirano, "Starch characteristics of the rice mutant du 2-2 Taichung 65 highly affected by environmental temperatures during seed development". Journal of Cereal Chemistry, vol. 80, pp. 184-187, 2003.

23. H.A.M. Wickramasinghe and T. Noda, "Physico chemical properties of starches from Sri Lankan rice varieties". Food Science and Technology Research, vol. 14, pp. 49-54, 2008.

24. G.M. Somaratne, B.D.R. Prasantha, G.R. Dunuwila, A.Chandrasekara, D.G.N.G. Wijesinghe and D.C.S. Gunasekara, "Effect of polishing on glycemic index and antioxidant properties of red and white basmati rice". Food Chemistry, vol. 237C, pp. 716-723, 2017.

25. M. J. M. Fari, D. Rajapaksa, and K. K. D. S. Ranaweera, "Quality characteristics of noodles made from selected varieties of Sri Lankan rice with different physicochemical characteristics". Journal of National Science Foundation, vol. 39, pp. 53-60, 2011.

26. T. T. B. Tran, K. J. Shelat, D. Tang, E. Li, R. G. Gilbert and J. Hasjim, "Milling of rice grains. The degradation on three structural levels of starch in rice flour can be independently controlled during grinding". Journal of Agricultural Food Chemistry, vol. 59, pp. 3964-3973, 2011.

27. P. C. Williams, R. H. Kilborn, P. W. Voisey and M. Kloek, "Measuring wheat hardness by revolutions per minute reduction". Cereal Chemistry, vol. 64, pp. 422-427, 1987.

28. A.D. Bettge, M.I. Giroux and C.F. Morris, "Susceptibility of waxy starch granules to mechanical damage". Cereal Chemistry, vol. 77, pp. 750- 753, 2000.

29. C.G. Oates and A.D. Powell, "Bioavailability of carbohydrate material stored in tropical fruit seeds". Food chemistry, vol. 56, pp. 405-414, 1996.

30. W.A. Atwell, L.F. Hood, D.R. Lineback, V.E. Marston and H. F. Zobel, "The terminology and methodology associated with basic starch phenomena". Cereal Food World, vol. 33, pp. 306-311, 1988.

31. J.L. Doublier, "Rheological properties of cereal carbohydrates". In: H. Faridi, J.M. Faubion (Eds.), Dough rheology and baked products Van Nostrand Reinhold. pp. 111-155, 1990.

32. M. Langton and A.M. Hermansson, "Microstructural changes in wheat starch dispersion during heating and cooling". Food Microstructure, vol. 8, pp. 29-39, 1989.

33. J.E. Kruger and D.W. Hatcher, "FY sedimentation test for evaluation of flour quality of Canadian wheats". Cereal Chemistry, vol. 72 pp. 33-37, 1995.

34. B.S. Luh and Y. Lui, "Rice flours in baking". In Rice production and utilization. AVI Publishing, 1980, pp. 470-485.

35. S. Varavinit, S. Shobsngob, W. Varanyanond, P. Chinachoti and O. Naivikul, "Effect of amylose content on gelatinization, retrogradation and pasting properties of flours from different cultivars of Thai rice". StarchStärke, vol. 55, pp. 410-415, 2003.

36. M.A. Fitzgerald, M. Martin, R.M. Ward, W.D. Park, and H.J. Shead, "Viscosity of rice flour: A rheological and biological study". Journal of Agricultural and. Food Chemistry, vol. 51, pp. 2295-2299, 2003.

37. T. Champagne, K. L. Bett-Garber, C. C. Grimm and A. M. McClung, "Effects of organic fertility management on physicochemical properties and sensory quality of diverse rice cultivars". Cereal Chemistry, vol. 84, pp. 320-327, 2007. 